\title{
2 ¿Cuáles son las principales causas de ese estancamiento?
}

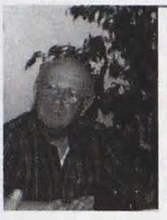

Hëctor Deda Hilrezl, Dipulado CDU

Es común atribuir toda la responsabilidad del estancamiento económico a factores externos, o a causas naturales. Pero esa explicación no cubre todos los aspectos que deben ser analizados. Varios de nuestros vecinos tienen algunos de estos problemas y crecen a ritmos mayores que los nuestros. Pienso que el fundamentalismo de mercado (que implica desconocer la verdadera naturaleza del mercado, de la misma forma en la que todos los fundamentalismos pierden la perspectiva de sus propias creencias) de la concepción gubernamental ha surcido los efectos que casi siempre produce en los palses que han puesto su fe en ello; las insuficiencias del llamado Consenso de Washington han sido aceptadas hasta por sus propios elaboradores. Se ha confiado que la simple apertura externa e interna de la economía bastaba para generar un crecimiento sostenido, sin medir las consecuencias antiproductivas de la política y la naturaleza misma de la estructura empresarial del país. Sin política de desarrollo es difícil obtener desarrollo. Sin un aparato del Estado que intervenga para suplir lo que el mercado no puede dar y a veces para garantizar que ciertas lógicas de mercado sean respetadas en una economía oligopólica, sin que tenga la fuerza para orientar el desarrollo, no puede existir desarrollo.

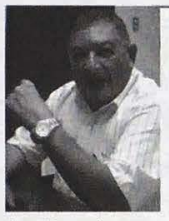

Jarge Barrazalbarra, UTEC

Son varias y posiblemente muchas, sin embargo considero que es importante señalar el abuso de políticas del modelo neoliberal, impuesto por el sistema predominante, para impulsar una economía de mercado en un entorno lleno de imperfecciones: monopolios abiertos y disfrazados, clientelismo político, falta de comperitividad empresarial, falta de transparencia en las transacciones económicas, la presencia de privilegios para algunos sectores y grupos de la actividad económica. Para $\mathrm{ml}$, es muy importante esa falta de visión social, que está implicita en la teoría del derrame, la economía no creció apuntando a favorecer el capital, y un país no crece cuando el número de pobres aumenta. A los fanáticos defensores del neoliberalismo habria que recordarles que en el mercado, la actividad económica se nutre de la demanda de ricos y pobres, por lo tanto no alcanzo a entender como puede crecer una economía en donde un alco sector poblacional no tiene capacidad de consumo.

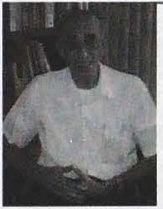
Javiar fbisate, UCA
La explicación viene del mediano plazo. La guerra asestó un duro golpe a los factores de producción gestadores del crecimiento económico en los tres grandes secrores de la economía. La década de los ochenta fue en realidad "una economía de guerra y una guerra a la economía", y en 1992 hubiera sido necesario responder con un programa de "economía de reconstrucción". En el año 1993 se publicó la matriz insumo producto 1990, que no indicaba en qué situación había quedado nuestra economía. Los análisis comparativos de las matrices 1990 y 1978 (antes de la guerra) mostraban que se estaba dando un proceso "terciarización" de la economía, y que era necesario reestructurar la economía y enderezar el crédito a los sectores con crédito de mediano plazo a la industria y agricultura. Sin embargo, ARENA obedeció las órdenes del Consenso de Washington: economía de libre comercio y apertura externa, cuando nuestros sectores estaban más debilitados. Tampoco hubo espacio para el Foro de Concertación Económica y Social.

Oswaldo Brand: "1997 ¿̨cambio de rumbo económico?" (ECA junio 1997; pP 535-349) presenta un análisis interesante sobre la situación económica y la falta de políticas adecuadas a su reestructuración. En ECA (septiembre 1997; pp. 799-819) yo publiqué un artículo: "¿Es el crecimiento la locomotora de nuestra economia", donde creo que cito a Oswaldo Brand. En los años de 1997-1999 se han publicado una serie de programas económicos: "Bases para un plan de Nación". Temas claves para un plan de nación: consulta especializada. Crecimiento estéril versus desarrollo (Funde). Crecimiento con participación. El Gobierno no prestó atención a estos programas académicos. En esos años comienzan a aparecer los Informes de Desarrollo Humano; el Vicepresidente asiste a la presentación y el resto del Gobierno sigue otro camino. En cuanto valga me permito citar un artículo más reciente: "Economía, sin plan, sin mercado y sin autocrítica" (ECA, junio 2003; pp. $541 .$. 


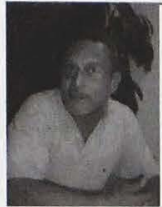

Carlos Briones, FLACSO

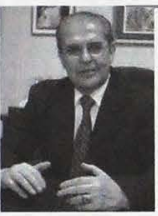

Rateel Rodriguez Loucel UTEC

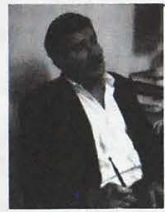

Rober to Rublo, FUNDE
Las causas en mi opinión son de dos tipos, en primer lugar, no puede negarse que el factor exrerno en los último años ha actuado desfavorablemente para la economía salvadoreña, por ser pequeña y abierta, se han tenido momentos de declive con los precios del café, la crisis asiática de 1997, y más recientemente, con la desaceleración de la economía norteamericana. El factor externo ha disminuido las oportunidades de crecimiento de la economia nacional. En segundo lugar, ésta tasa de crecimiento refleja la imposibilidad, como pals, de encontrar una nueva forma de inserción económica, un modelo de acumulación económica que sustituya el que entró en crisis desde hace ya 15 años, y que estaba basado en productos del secror agroexportador.

En la administración del presidente Cristiani se quiso apuntar a la diversificación de productos agricolas no tradicionales, pero la apreciación del ripo de cambio real creó un boom hacia el mercado interno y hacia acrividades no necesariamente transables, fue entonces que vino el boom de la construcción de viviendas y centros comerciales. La apreciación cambiaria limitó enormemente las posibilidades de diversificar una oferta exportable agrícola y la mayor parte del crecimiento del primer quinquenio de los noventa fue fundamentado en una recuperación del consumo nacional, estuvo fundado en el mercado y la demanda interna. Después vino una caída, porque no se puede seguir creciendo teniendo como destino de la producción sólo el mercado nacional y el centroamericano. Pot el momento no se ha logrado encontrar las actividades capaces de producir un cambio estructural en la economía salvadoreña. Por ejemplo, bajo el declive del ańil, se dio el cambio estructural del café, se transformó la agricultuta y se volvib eficiente porque tenfamos las condiciones naturales para hacerlo. Eso permitió el crecimiento de una econom/a agroexportadora durante mucho tiempo. Luego vino el momento de la integración centroamericana que cré condiciones para la diversificación de la producción industrial salvadoreña, se crearon condiciones de cambio estructural. Es esa condición de cambioestructural to que actualmente no se tiene.

La baja productividad, reducida comperitividad, poca capacidad exportadora, baja propensión interna a ahorrar y a invertir, poca afluencia de inversión extranjera directa, poca rentabilidad del agro, inestabilidad social, reducida inversión en capital humano, desaceleración de la econom la mundial (en particular la de Estados Unidos), reducción drástica de los términos de intercambio, actuar reactivo en el manejo del quehacer económico, ambiente desfavorable en términos de seguridad física y jurldica, pérdida de la política monetaria para enfrentar los ciclos depresivos de la economia, desviación del crédito hacia el corto plazo por una práctica bancaria de menor de riesgo, ete.

Hay varias razones. A nivel externo, sabemos que la economía mundial entró en una desaceleración económica, especialmente la economía norteamericana. La baja en los precios de las materias primas a nivel mundial nos afectó, sobre todo, el precio del café, la azúcar y el crecimiento del precio del petróleo, son factores externos que ha frenado nuestro crecimiento. Pero también hay causas internas producto de una mala política y deformaciones históricas. Una de ellas es la debilidad y desarticulación de nuestro aparato productivo, siempre ha sido un aparato volcado al exterior, condición que provoca que por cada desaceleración externa que aparezca el impacto interno sea mayor.

El problema ha sido esa desarticulación de la economia, porque puede tenerse un crecimiento en el sector construcción, comercio, pero por el tipo coeficiente de importación, estos sectores, a veces dinámicos, están más relacionados con el exrerior que con el interior porque no generan mucha demanda hacia adentro. Si la construcción ruviera un coeficiente de importación bajo, demandarla muchas cosas internas, pero no ha sido el caso.

La estructura económica de nuestros país es vulnerable, es una estructura económica desarticulada, una economía bastante desintegrada internamente, muy concentrada en la capital, donde la dinámica económica no llega a todos los territorios en general. Estas tres deformaciones históricas: vulnerabilidad, desarticulación y centralización del aparato productivo, han sido determinantes para marcar el crecimiento. Existe una cuarta característica de deformación: la concentración, me refiero a que los buenos negocios, los negocios rentables, los negocios dinánicos se concentran en pocos sectores $y$ en pocas personas o pocos grupos empresariales.

A estos cuatro fenómenos que generan una deformación estructural, se añaden los errores de la polfrica económica, de una visión que en los últimos tiempos magnificó al mercado y dejó a los sectores agrarios e industriales domésticos sin apoyo, se llegó a decir que estos sectores no tenían fururo, que era mejor dedicarse a inversiones y servicios de otro tipo. Se abandonó el agro y al sector de la industria doméstica, dos sectores fisertes que, en una economía como la nuestra, son importantes. De alguna manera, estos secrores salieron afectados, son las que menos dinamismo han reflejado. Tenemos, además otro problema menos histórico, el tema de las remesas. Más del ochenta porciento de la población recibe remesas, y un buen porcentaje de ellas se las gasta en bienes de consumo. Generando una demanda externa. 